\title{
Scientifically unfounded precaution drives European Commission's recommendations on EDC regulation, while defying common sense, well-established science and risk assessment principles
}

Note: The following text was prepared in response to the present discussion regarding the European Commission's recommendations on the so called "endocrine disrupting chemicals" and is supported by the editors and associate editors of Toxicology in Vitro, Bas Blaauboer, Frank Barile, Daniel Acosta Jr, Billy Day and Kerstin Stemmer. It also refers to a letter sent in response to these recommendations and that was undersigned by a group of toxicologists. This or a similar editorial will appear in other toxicology and pharmacology journals.

Corresponding author for this editorial:

Prof. Dr. Bas J. Blaauboer

Editor of Toxicology in Vitro,

c/o: Institute for Risk Assessment Sciences,

Division of Toxicology, Utrecht University,

PO Box 80.177, 3508 TD Utrecht,

The Netherlands.

We, the undersigned editors of prominent journals of pharma cology and toxicology, are drawing your attention to the imminent decisions by the European Commission to enforce a regulatory framework for so called endocrine disrupting chemicals (EDCs). The currently drafted framework is based on virtually complete ignorance of all well established and taught principles of pharmacology and toxicology, of opinions raised by the European Commission's own competent expert authority (European Food Safety Authority (EFSA, 2013)), and of critical statements made by member countries, while avoiding asking for support from the European Commission's own scientific expert committees.

As a statement, and as emphasized by others before, "endo crine disruption" is not a toxicologically defined endpoint but a mode of action that may or may not result in adverse effects. In itself, the mode of action concept implies the necessary exis tence of a threshold as experimentally proven for numerous other non genotoxic agents including EDC's. Moreover, endocrine systems play a fundamental role in the physiological response to changes in the environment with the aim of keeping an organ ism's biology within the homeostatic space. It is the task of tox icologists to make the distinction between those effects that are within this adaptive range and effects that go beyond the bound aries of this space and thus can be called adverse. Such adverse effects can be observed in adequately designed and performed toxicity studies.

While we agree that a concern for possible EDCs is sensible and important, we also think that the identification and regulation of such substances should depend on (a) the definition of adverse ef fects that are relevant to whole human or animal organisms and not to isolated test systems of unknown homeostatic significance and (b) on a characterization of real life potency and therefore of thresholds of concern.
In contrast, the currently drafted EU framework for EDCs fore sees a priori regulation of agents that may show presumably endo crine mediated effects in some experimental system (in vitro, in silico, in vivo, etc.), and under the a priori default assumption of no thresholds. This approach is based on a very small number of publications (Sheehan, 2006; Vandenberg et al., 2012; Zoeller et al., 2012; Birnbaum, 2013) that lack the required scientific robust ness needed for such an important piece of legislation that is sweeping in nature, will set an unforeseen precedence, and finally will have profound ramifications for everyone's livelihood. Furthermore, the regulatory draft specifically states that the iden tification of an endocrine disruptor relies "on the "demonstration of an adverse effect for which there is convincing evidence of a biologi cally plausible causal link to an endocrine disrupting mode of action and for which disruption of the endocrine system is not a secondary consequence of other non endocrine mediated systemic toxicity. Relevance of the data to humans should be assumed in the absence of appropriate data demonstrating non-relevance."

As all scientists should know, it is biologically and statistically impossible to demonstrate "absence of effect" and thus "absence of relevance". The mere statement demonstrates the lack of atten tion paid by the European Commission to the weight of scientific evidence that clearly demonstrates the presence of a threshold for non genotoxic compounds including EDCs (Rhomberg et al., 2011; Rhomberg and Goodman, 2012; Borgert et al., 2012; Piersma et al., 2011; Boobis et al., 2009), as well as to the scientific detail with regard to the physiological and statistical implausibility of the approach taken. In fact, any scientist familiar with the over whelming biochemical complexity of life understands that the healthy homeostasis of an organism results from an orchestrated network of myriad thresholds for every component substance. 
On this account, a nucleus of scientists sent an open letter on June $18,2013^{1}$ to Prof. Anne Glover, Chief Scientific Advisor to the President of the European Commission Manuel Barroso, ${ }^{2}$ pointing out the major deficiencies of the drafted EU framework, and the wor risome ramifications this draft could have for science, the economy, and human welfare the world over.

Although some readers may shrug and think this is not impor tant and not their problem, it soon could be. Regulations that pro foundly affect human activities, that legally impose significant fines and even detention, should not be based on irrelevant tests forced to be regarded as relevant by administrative dictates, and on arbitrary default assumptions of no thresholds. Such standards would be contrary not only to science, but to the very principles of an enlightened governance and social contract. Not only scientists but society itself would pay dearly if unscientific approaches were to undermine our everyday practice of science, and the stringency of data analysis and evaluation developed by scientific thinking over the past centuries. In the present instance, the very credibility of thorough and robust teaching, research, and scientific analysis is questioned. This calls for action, and as beneficiaries of public sup port it is the utmost responsibility of us scientists to resist and counteract any efforts that undermine the core of science and its continuing promise for the betterment of the human condition and of the planet.

\section{Authors}

Daniel R. Dietrich, Editor in Chief, Chemico Biological Interactions

Sonja von Aulock, Editor in Chief, ALTEX

Hans Marquardt, Editor in Chief, Toxicology

Bas Blaauboer, Editor Europe, Toxicology in Vitro

Wolfgang Dekant, Editor in Chief, Toxicology Letters

James Kehrer, Editor in Chief, Toxicology Letters

Jan Hengstler, Editor in Chief, Archives of Toxicology

Abby Collier, Section Editor, Chemico Biological Interactions

Gio Batta Gori, Editor in Chief, Regulatory Pharmacology and Toxicology

Olavi Pelkonen, Editor in Chief, Frontiers in Predictive

Toxicology

Florian Lang, Editor in Chief, Toxins

Frans P. Nijkamp, Editor in Chief, European Journal of Pharmacology
Kerstin Stemmer, Assoc. Editor, Toxicology in Vitro Albert Li, Section Editor, Chemico Biological Interactions Kai Savolainen, Editor for Europe and rest of the World, Human and Experimental Toxicology

A. Wallace Hayes, Editor for the Americas, Human and Experi mental Toxicology and Editor in Chief, Food and Chemical Toxicology

Nigel Gooderham, Editor in Chief, Toxicology Research

Alan Harvey, Editor in Chief, Toxicon

\section{References}

Birnbaum, L., 2013. When environmental chemicals act like uncontrolled Medicine. Trends in Endocrinology and Metabolism. http://dx.doi.org/10.1016/ j.tem.2012.12.005 (Epub ahead of print).

Boobis, A.R., Daston, G.P., Preston, R.J., Olin, S.S., 2009. Application of key events analysis to chemical carcinogens and noncarcinogens. Critical Reviews in Food Science and Nutrition 49 (8), 690-707.

Borgert, C.J., Sargent, E.V., Casella, G., Dietrich, D.R., McCarty, L.S., Golden, R.J., 2012. The human relevant potency threshold: reducing uncertainty by human calibration of cumulative risk assessments. Regulatory Toxicology and Pharmacology 62 (2), 313-328.

European Food Safety Authority Scientific Committee, 2013. Scientific opinion on the hazard assessment of endocrine disruptors: scientific criteria for identification of endocrine disruptors and appropriateness of existing test methods for assessing effects mediated by these substances on human health and the environment. EFSA Journal 11 (3), 3132-3216.

Piersma, A.H., Hernandez, L.G., van Benthen, J., Muller, J.J.A., van Leuween, F.X.R., Vermiere, T.G., van Raaij, M.T.M., 2011. Reproductive toxicants have a threshold of adversity. Critical Reviews in Toxicology 41 (6), 545-554.

Rhomberg, L.R., Goodman, J.E., Haber, L.H., Dourson, M., Andersen, M.E., Klaunig, J.E., Meek, B., Price, P.S., McClellan, R.O., Cohen, S.M., 2011. Linear low-dose extrapolation for noncancer health effects is the exception, not the rule. Critical Reviews in Toxicology 41 (1), 1-19.

Rhomberg, L.R., Goodman, J.E., 2012. Low-dose effects and nonmonotonic doseresponses of endocrine disrupting chemicals: has the case been made? Regulatory Toxicology and Pharmacology 64, 130-133.

Sheehan, D.M., 2006. No-threshold dose-response curves for nongenotoxic chemicals: findings and applications for risk assessment. Environmental Research 100, 93-99.

Vandenberg, L.N., Colborn, T., Hayes, T.B., Heindel, J.J., Jacobs Jr., D.R., Lee, D.H., Shioda, T., Soto, A.M., Vom Saal, F.S., Welshons, W.V., Zoeller, R.T., Myers, J.P., 2012. Hormones and endocrine-disrupting chemicals: low-dose effects and nonmonotonic dose responses. Endocrine Reviews 33 (3), 378-455.

Zoeller, R.T., Brown, T.R., Doan, L.L., Gore, A.C., Skakkebaek, N.E., Soto, A.M., Woodruff, T.J., Vom Saal, F.S., 2012. Minireview: endocrine-disrupting chemicals and public health protection: a statement of principles from the endocrine society. Endocrinology 153 (9), 1-14.

\footnotetext{
${ }^{1}$ Open Letter to Prof. Anne Glover (to be included in each Journals own format) of June 18, 2013.

2 http://ec.europa.eu/commission_2010-2014/president/chief-scientific-adviser/.
} 
Annex 1: open letter of 18 June 2013 to Prof. Glover (see footnote 1 in Editorial).

RE: Draft regulation on endocrine active chemicals June 18, 2013

Dear Prof. Glover,

We, the undersigned are writing to draw your attention to im minent decisions by the European Commission to set a regulatory framework for so called endocrine disrupting chemicals. We are concerned that the approach proposed could rewrite well accepted scientific and regulatory principles in the areas of toxicology and ecotoxicology without adequate scientific evidence justifying such a departure from existing practices.

First of all, we want to emphasize that "endocrine disruption" is not a toxicological endpoint, but one of many mechanisms which may cause adverse effects. In addition, we recognise that such a policy initiative is highly technical and complex and requires an understanding of the modes of action for endocrine disruption and their significance. It also implies the in depth involvement not only of toxicological disciplines but also of environmental sciences and thus requires scientific input from experts in this area. The undersigned are concerned that the Commission's scientific committees have so far not been consulted by the Commission when drafting such regulations. What is even more disturbing is that, where a scientific advisory body such as EFSA has been con sulted, critical elements of this body's opinion are ignored. For ex ample, in assessment of chemicals with endocrine activity, EFSA supported a substance specific risk assessment approach integrat ing exposure and adverse effects instead of developing horizontal criteria for defining whether a substance is an "endocrine disrup tor". Development of horizontal lists ignores the long standing principle that an assessment of a substance should be based on data obtained from toxicity testing on this specific substance and derived information on potency.

If the Commission will adopt a policy stating that it is impos sible to define a safe limit or threshold for a substance with clas sified as endocrine disruptor, this would reverse current scientific and regulatory practices and, more importantly, ignore broadly developed and accepted scientific development and ac cepted knowledge regarding thresholds of adversity. Moreover, the latter approach may not only apply to potential EDCs but rather would apply to all chemical substances and thus nullify decades of experience and repeatable observations in expo sure response relationships in pharmacology and toxicology and well established and widely proven procedures in hazard and risk assessment.

It also appears that the Commission will propose that identifica tion of an in vitro effect without a causal relationship to adversity in an intact organism may be sufficient to classify a substance as an "endocrine disruptor". This would not only represent a rewriting of the rules and accepted practices of toxicology, which rely on well defined adverse effects observed in adequately performed studies, but also would be contrary to all accumulated physiological understanding.

This leaves us concerned that there is neither a scientific basis nor broad support by scientists established in risk assessment be hind the approach of setting horizontal criteria and the lists of con firmed and suspected "endocrine disruptors".

We have noted your important interventions on the need for scientific evidence to be at the heart of EU policy and are therefore writing to urge your review of the emerging policy to ensure that the opinion of relevant scientific committees and member states authorities are taken into account.

The following individuals are supporting this initiative:
Antero Aitio, Dr. Med. Sc., Professor h.c., former scientist/ medical officer at the International Programme on Chemical Safety, World Health Organization; former team leader, Fin nish Institute of Occupational Health; former Unit Chief of the Monographs Programme, International Agency for Re search on Cancer

Herman Autrup, Professor, PhD ATS, President International Un ion of Toxicologists, former member SCHER, AFC Panel of EFSA, Institute of Public Health, University of Aarhus, Denmark

Susan, Barlow, Ph.D., former member of EFSA Scientific Com mittee (2003 2012), Brighton, UK

Diane Benford, Dr., member, chair CONTAM Panel of EFSA, Head of Chemical Risk Assessment Unit, Food Standards Agency, London, UK

Ole J. Bjerrum, DMSc, Professor of Pharmacology, University of Copenhagen, Denmark

Sir Colin Berry, Prof. Emeritus of Pathology, Queen Mary, Uni versity of London, UK

Bas J. Blaauboer, Prof. Dr., Doerenkamp Z Zbinden Chair on Alter natives to Toxicity Testing, Institute for Risk Assessment Sciences, Division of Toxicology, Utrecht University, The Netherlands

Hermann M. Bolt, Prof. Dr. med., Dr. rer. nat., Chair of the Scien tific Committee for Occupational Exposure Limits, SCOEL (DG Em ployment), Leibniz Research Centre for Working Environment and Human Factors (IfADo) at the TU Dortmund, Germany

Alan Boobis, Prof., OBE, PhD, FSB, FBTS, member CONTAM Panel of EFSA, Centre for Pharmacology \& Therapeutics, Department of Medicine, Imperial College London, UK

Christopher J. Borgert, Ph.D., President \& Principal Scientist, Ap plied Pharmacology and Toxicology, Inc., Research Assistant Scien tist, Department of Physiological Sciences, College of Veterinary Medicine, Gainesville, FL, USA

Alexander Bürkle, Prof. Dr., Chair of Molecular Toxicology De partment of Biology, University of Konstanz, Germany

Michèle Bouchard, Ph.D., Associate Professor, Head of the Chair in Toxicological Risk Assessment and Management and Head of the Biomarker Unit of the Xenobiotics and Nanoparticles Platform, De partment of Environmental and Occupational Health, Faculty of Medicine, University of Montreal, Canada

Thomas Colnot, Ph.D., ERT, CiS Toxicology, Castro, Chile

Brian Cummings, Ph.D., Assistant Professor, Department of Pharmaceutical and Biomedical Sciences, University of Georgia, Athens, GA, USA

Slawomir Czerczak, Prof. Dr., Chair for Group of Experts for Che mical Agents of Polish Intersectoral Commission for MAC and MAI Values, Head of Department of Chemical Safety, Nofer Institute of Occupational Medicine Lodz, Poland

Gisela H. Degen, Prof. Dr., member SCCS, Leibniz Research Cen tre for Working Environment and Human Factors (IfADo) at the TU Dortmund, Germany

Wolfgang Dekant, PhD, Professor of Toxicology, former member SCHER, CSTEE, member SCHENIHR, Department of Toxicology, Uni versity of Würzburg, Germany

Lennart Dencker, Prof. Dr., Department of Pharmaceutical Bios ciences, Uppsala University, Uppsala, Sweden

Daniel Dietrich, Prof. Dr., Ph.D., Professor of Human and Envir onmental Toxicology, Member of SCENIHR, Former Chair of the OECD Endocrine Disruption and Ecotoxicology EDTA VMG Non Animal of the OECD, Member Presidential Expert Group AOAC, Fa culty of Biology, University of Konstanz, Germany 
Daniel R. Doerge, Ph.D., National Center for Toxicological Re search, Jefferson, AR, USA (affiliation is given for identification pur poses only)

Eugenia Dogliotti, Dr., Member CONTAM Panel of EFSA, Istituto Superiore di Sanità, Environment \& Primary Prevention Dept., Unit of Molecular Epidemiology, Roma, Italy

Jose L. Domingo, Professor and Director, Laboratory of Toxicol ogy and Environmental Health, School of Medicine, Universitat "Rovira i Virgili", Reus, Spain

Johanna Fink Gremmels, Prof. Dr., Utrecht University, Faculty of Veterinary Medicine, Institute for Risk Assessment Sciences, Divi sion Toxicology, Veterinary Pharmacology, Pharmacotherapy and Toxicology, Utrecht, The Netherlands

Hermann Fromme, Prof. Dr., Department of Chemical Safety and Toxicology, Bavarian Health and Food Safety Authority, Munich

Corrado Galli, Pof. Dr., Dean, Faculty of Pharmaceutical Sciences, Lab. Toxicology, Department of Pharmacological and Biomolecular Sciences, University of Milan, Italy

David Gott, Dr., member ANS Panel of EFSA, Head of Toxicology Team, Chemical Risk Assessment Unit, Food Standards Agency, London, UK

Gio Batta Gori, DSc, MPH, ATS, Editor, Regulatory Toxicology and Pharmacology

Bettina Grasl Kraupp, Prof. Dr., ERT, Institute for Cancer Re search Medical University of Vienna, Austria

Helmut Greim, Prof. Dr., member RAC ECHA, former chair MAK Commission, former chair SCHER, former member CSTEE, member SCHER, Technische Universität München, Senatskommission der DFG zur Prüfung gesundheitsschädlicher Arbeitsstoff, Freising, Germany

Heidrun Greim, Dr., Wissenschaftliches Kommissionssekretariat der Ständigen Senatskommission der DFG zur Prüfung gesund heitsschädlicher Arbeitsstoffe, Karlsruher Institut für Technologie (KIT), Abteilung Lebensmittelchemie und Toxikologie, Institut für Angewandte Biowissenschaften, Freising Weihenstephan, Germany

G.M.M.Groothuis, Prof. Dr., Professor in Drug Metabolism and Toxicology, Department of Pharmacy, Groningen Research Institute of Pharmacy, Division Pharmacokinetics, Toxicology and Targeting, University of Groningen, The Netherlands

Helen Håkansson, Professor, Head of Unit, Karolinska Institutet, Institute of Environmental Medicine, Environmental Health Risk Assessment Unit, Stockholm, Sweden

Steen Honoré Hansen, Prof. D.Sc., Analytical Biosciences, Department of Pharmacy, Faculty of Health and Medical Sciences, University of Copenhagen, Denmark

Wolfgang Heger, Dr., Umweltbundesamt, Berlin, Germany

Björn Hellman, Ph.D., Professor of Toxicology, Department of Pharmaceutical Biosciences, University of Uppsala, Sweden (affiliation is given for identification purposes only)

Jan G. Hengstler, Prof. Dr., Leibniz Research Centre for Working Environment and Human Factors, IfADo, Dortmund, Germany

Magnus Ingelman Sundberg, PhD, BSc.Med, Professor and Sec tion Head, Vice Dean (Recruitment), Karolinska Institutet, Section of Pharmacogenetics, Department of Physiology and Pharmacol ogy, Stockholm, Sweden

Colin Janssen, Prof. Dr., former member CSTEE, member SCHER, Ghent University, Department Applied Ecology and Environmental Biology, Laboratory of Environmental Toxicology and Aquatic Ecol ogy, Ghent, Belgium

Risto Juvonen, PhD, School of Pharmacy Faculty of Health Sciences University of Eastern Finland, Kuopio, Finland

James Kehrer, Professor and Dean, Faculty of Pharmacy \& Phar maceutical Sciences, Katz Centre for Pharmacy \& Health Research, University of Alberta, Edmonton, AB, Canada
Hannu Kiviranta, Ph.D., Unit head, National Institute for Health and Welfare/ Department of Environmental Health/ Chemical Exposure, Kuopio, Finland

Hannu Komulainen, Research professor, former member SCHER, National Institute for Health and Welfare, Department of Environ mental Health, Kuopio, Finland

Hans Lepper, Dr., Bayerisches Landesamt für Gesundheit und Lebensmittelsicherheit, SG K3: Forschungskoordination/Zentral stelle Risikoanalyse, Erlangen, Germany

Beatriz Silva Lima, Prof. Dr., Lisbon University, Faculty of Phar macy, Lisbon, Portugal

Jan Linders, Dr., member SCHER, formerly National Institute for Public Health and the Environment (RIVM), The Netherlands

Marcello Lotti, MD, Professor, University of Padua, Medical School, Padua, Italy

Marina Marinovich, Prof. Dr., Faculty of Pharmaceutical Sciences, Lab. Toxicology, Department of Pharmacological and Bio molecular Sciences, University of Milan, Italy

Angelo Moretto, Prof. Dr., Department of Biomedical and Clini cal Sciences, Università degli Studi di Milano, Milano, Italy

Paquale Mosesso, Associate Professor of Genetics, member ANS Panel of EFSA, Department of Ecological and Biological Sciences, University of Tuscia, Viterbo, Italy

Mikko Nikinmaa, Prof. Dr., Department of Biology, University of Turku, Finland

Marc Pallardy, Prof. Dr., INSERM UMR 996, University Paris Sud, Faculty of Pharmacy, Chatenay Malabry, France

Markku Pasanen, Prof. Dr., University of Eastern Finland, Faculty of Health Sciences, School of Pharmacy, Kuopio, Finland

Olavi Pelkonen, Professor of Pharmacology, Department of Pharmacology and Toxicology, University of Oulu, Oulu, Finland Hannu Raunio, Prof. Dr., University of Eastern Finland, Faculty of Health Sciences, School of Pharmacy, Kuopio, Finland

Ivonne M.C.M. Rietjens, Prof. dr. ir., Professor in Toxicology, member ANS Panel of EFSA, Wageningen University AFSG/Division of Toxicology, Wageningen, The Netherlands

Konrad Rydzynski, Prof. Dr. med., Coordinator of the European Network of Excellence ECNIS (Environmental Cancer Risks, Nutri tion and the Individual Susceptibility), member SCENIHR, Director of the Nofer Institute of Occupational Medicine, Lodz, Poland

Edward V. Sargent, Dr., MPH, PhD DABT, Adjunct Full Professor, School of Public Health, Rutgers University, NJ, USA

Tinaa Santonen, MD, PhD, MSc in Applied Toxicology Team Lea der, Chemical Safety, Finnish Institute of Occupational Health, Finland

Josef Schlatter, Dr., member of EFSA Scientific Committee, Zürich, Switzerland

Dieter Schrenk, MD PhD, Professor of Toxicology, member CON TAM Panel of EFSA, Food Chemistry and Toxicology University of Kaiserslautern, Germany

Richard M Sharpe, Prof. Dr., MRC Centre for Reproductive Health, The Queen's Medical Research Institute, University of Edin burgh, Scotland, UK

Andrzej C Skladanowski, PhD, Prof. Dr., Medical University of Gdansk Intercollegiate Faculty of Biotechnology UG MUG, Depart ment of Molecular Enzymology, Gdansk, Poland

Ralf Stahlmann, Prof. Dr. med., Institut für Klinische Pharmako logie und Toxikologie, Charité Universitätsmedizin Berlin, Germany

Frank M. Sullivan, BsC (Hons), FBTS, formerly UK Specialist in Reproductive Toxicology

James A. Swenberg, DVM, PhD, DACVP, Kenan Distinguished Professor of Environmental Sciences and Engineering, Gillings School of Global Public Health, University of North Carolina, Chapel Hill, NC, USA 
Emanuela Testai, Dr., former member SCHER, CSTEE, member SCENIHR, Istituto Superiore di Sanità, Environment \& Primary Prevention Dept., Mechanisms of Toxicity Unit, Roma, Italy Jouko Tuomisto, MD, PhD, Professor emeritus, Department of Environmental Health, THL (National Institute for Health and Wel fare), Kuopio, Finland

N.P.E. Vermeulen, Prof. Dr., AIMMS/ LACDR Section of Molecular Toxicology, Dept. of Chemistry \& Pharmaceutical Sciences, VU Uni versity, Amsterdam, The Netherlands

Marco Vighi, Prof. Dr., former member SCHER, Department of Earth and Environmental Sciences, University of Milano Bicocca, Milano, Italy

Matti Viluksela, Prof. Dr., former member SCHER, National Insti tute for Health and Welfare Department of Environmental Health,
Kuopio, Finland and University of Eastern Finland Department of Environmental Science Kuopio, Finland

Wolfgang Völkel, PD Dr., ERT, Bayerisches Landesamt für Gesundheit und Lebensmittelsicherheit, Sachgebiet Chemikaliensi cherheit und Toxikologie/Biomonitoring, München, Germany J.C. Vos, Dr., Dept. of Chemistry \& Pharmacochemistry, AIMMS Section of Molecular Toxicology, Vrije Universiteit, Amsterdam, The Netherlands

Wojciech Wasowicz, Prof. Dr., President of the Polish Society of Toxicology, Nofer Institute of Occupational Medicine, Lodz, Poland 